\title{
ADQUISICIÓN DE COMPETENCIA PARA LA MICROPROPAGACIÓN DE STANHOPEA TIGRINA, LAELIA ANCEPS, EPIDENDRUM VEROSCRIPTUM Y CATTLEYA X ESBETTS (ORCHIDACEAE)
}

\author{
Mario Sinaí Tinoco JuÁrez \& Martín Mata Rosas ${ }^{1,2}$ \\ ${ }^{1}$ Laboratorio de Cultivo de Tejidos, Unidad de Recursos Forestales, Instituto de Ecología, A.C., \\ Xalapa, Veracruz, 91070, México \\ 2Author for correspondence: martin.mata@inecol.edu.mx
}

\begin{abstract}
Regeneration protocols were established from the in vitro culture of protocormos of Stanhopea tigrina, Epidendrum veroscriptum, Laelia anceps and Cattleya $\mathrm{x}$ esbetts using the Murashige and Skoog culture medium added with different concentrations of $\mathrm{N}^{6}$-benzyladenine (BA) $(0,1,3$, y $5 \mathrm{mg} / \mathrm{l})$ y 2,4 dichlorofenoxiacetic acid (2,4-D). The regeneration and formation of new plantlets was achieved by multiple shoot and also through protocorm like bodies (PLBs). For each species the best concentration of growth regulator, as well as the time of acquisition of competence for the highest shoot formation and/or PLBs were determined. As far as we know there are no reports with reference to the acquisition of competence within the Orchidaceae family that allow the production of many individuals within the shortest time and reducing the financial cost. This could form the base that covers their commercial demand and also contribute to the conservation and sustainable use of mainly wild species.
\end{abstract}

PALABRAS ClAVE: orquídeas, protocormo, adquisición de competencia, cultivo de tejidos, micropropagación

\section{Introducción}

La familia Orchidaceae es una de las más grandes y más diversas familias de plantas, se estima que existen aproximadamente 800 géneros y alrededor de 25,000 especies (Arditti, 1992; Dreesler, 1993; Espejo et al., 2002; Dixon et al., 2003). Es una familia cosmopolita y prácticamente se distribuye en todo el mundo con excepción de los hielos permanentes y los desiertos (Quintanar, 1961). En México se distribuyen alrededor de 1,200 especies de orquídeas (Espejo et al., 2002), con un endemismo de 40\%; y los estados con mayor diversidad de orquídeas son: Chiapas, Oaxaca, Veracruz, Puebla, Hidalgo, San Luis Potosí, Guerrero, Michoacán, Jalisco, Nayarit y Sinaloa (Soto, 1996). A pesar de ser una de las familias más grandes de plantas con flores, la distribución de las orquídeas ha disminuido notablemente en nuestros días, estos cambios se deben principalmente a la alteración y destrucción del hábitat, además muchas de las poblaciones silvestres están siendo seriamente afectadas por el volumen de individuos reproductores que se extraen para satisfacer la demanda comercial de que son objeto debido a que son altamente apreciadas como especies ornamentales. Lo anterior trae como consecuencia el lento o nulo restablecimiento de las poblaciones, debido a que presentan una baja tasa de crecimiento, ciclos de vida relativamente largos y escaso reclutamiento de nuevos individuos bajo condiciones naturales, llegando a ocasionar que un gran número de ellas se encuentren en peligro de extinción (IUCN /SSC Orchid Specialist Group 1996; Sosa y Platas, 1998; Ávila y Oyama, 2002).

La rareza y belleza de las orquídeas han atraído la atención muchos horticultores y/o coleccionistas, en muchos casos las poblaciones de diversas especies han sufrido sobrecolectas exhaustivas para satisfacer el comercio, éste tráfico ilegal de ejemplares silvestres ha aumentado principalmente desde la segunda mitad del siglo XX, teniendo como consecuencia que muchas poblaciones naturales hayan disminuido considerablemente, de hecho en algunos casos, poblaciones enteras han desaparecido (Betchtel et al., 1981; IUCN/ SSC Orchid Specialist Group, 1996; Ospina, 1996; Hágsater y Soto, 2001). Los más afectados han sido las especies con alto potencial ormanental, entre alguno de los géneros que incluyen especies de alta importancia hortícola se encuentran: Laelia (por sus flores grandes y espectaculares), Oncidium (por la belleza de sus inflorescencias y la potencialidad de crear híbridos), Rhynchostele (por la belleza de sus 
flores) Encyclia (por la sencillez de las mismas) y Stanhopea (por la rareza y extravagancia de sus flores) (Jiménez et al., 1998).

La conservación de orquídeas no es una tarea fácil y principalmente en países tropicales como México, donde se encuentran la mayor diversidad de especies y es también donde la problemática es más grave. En México la alteración del hábitat y la sobrecolecta de orquídeas ha conducido a que 182 especies de orquídeas se encuentran dentro de algún estatus de conservación; se considera que una especie está extinta en el medio silvestre, 16 en peligro de extinción, 58 amenazadas y 107 sujetas a protección especial (SEMARNAT, 2002). En un gran número de mercados públicos en todo México existe una venta masiva de individuos colectados ilegalmente, en donde es posible encontrar especies en peligro de extinción, por lo que esta actividad se ha convertido en una de las principales causas de la disminución del número de individuos y poblaciones de las especies de orquídeas mexicanas (Hágsater \& Soto 2001, Salazar 2003). En muchas ocasiones el uso que se le da a estas especies es únicamente durante el periodo de floración, una vez que la flor se marchita, es muy frecuente que la planta sea desechada. En otras ocasiones el poco conocimiento que la gente tiene sobre el cultivo de las plantas, hace casi imposible la supervivencia de la misma. Claros ejemplo de esta situación son las siguientes especies:

Stanhopea tigrina Bateman es una especie endémica de nuestro país, muy apreciada por su valor ornamental, lo que ha provocado una sobrecolecta de individuos silvestres y una comercialización ilegal (Soto 2002); actualmente se encuentra bajo protección especial por parte del gobierno federal Mexicano (SEMARNAT, 2002), por lo cual, es fundamental buscar alternativas para su conservación y preservación.

Laelia anceps Lindley es una especie endémica mexicana y una de las más utilizadas en hibridización (Halbinger y Soto, 1997), con un alto potencial ornamental y de gran interés económico; aunque no se encuentra catalogada dentro de la NOM-059ECOL-2001, las presiones de colecta y comercio ilegal han disminuido considerablemente sus poblaciones, por lo que es preciso estudiar esta especie y ofrecer alternativas para su cultivo y comercialización.

El género Epidendrum está muy extendido en nuestro país, dentro de las especies que se distribuyen en México se encuentra E. veroscriptum Hágsater, a pesar que no se encuentra bajo alguna categoría de protección por parte del gobierno Mexicano, tiene un alto potencial ornamental y económico (García-Cruz y Sánchez, 1999), además que el hábitat donde se distribuye, el bosque mesófilo de montaña, es uno de los ecosistemas que están en riesgo de desaparecer y por consecuencia, las especies que contiene.

Finalmente, Cattleya x Esbetts es un híbrido muy apreciado como planta de ornato, de gran importancia comercial debido al tamaño, color y belleza de sus flores, popular por su fácil cultivo (Hágsater, 1971), el cual se puede comercializar por productores nacionales y generar recursos económicos importantes.

En este contexto, la conservación y uso sustentable de germoplasma valioso se ha planteado como una medida inaplazable y prioritaria; la conservación se puede englobar en dos grandes puntos: Se ha intentado realizar una efectiva conservación in situ a través del mantenimiento de áreas naturales protegidas, realizando programas de recuperación de especies, restauración de hábitats, control de especies invasoras y manejo de poblaciones de plantas y ecosistemas; sin embargo, cuando lo anterior no es posible llevar a cabo con éxito, o se pretende reforzar los esfuerzos realizados, se puede recurrir a la conservación ex situ; en este sentido los jardines botánicos y otras instituciones de investigación, tienen una importante función, buscando rescatar el germoplasma amenazado mediante el mantenimiento de colecciones vivas, estableciendo bancos de semillas, suministrando material para diferentes propósitos con el fin de eliminar o reducir la presión de colecta de que son objeto, cultivando aquellas especies con semillas recalcitrantes que no pueden ser mantenidas en bancos de semillas y a través de la propagación y multiplicación a través de las técnicas de cultivo de tejidos (Wyse, 2001).

El Cultivo de Tejidos Vegetales (CTV) es una herramienta biotecnológica cuyo fundamento se basa en la totipotencialidad celular, lo que permite mantener, en un medio de cultivo químicamente definido, cualquier estructura vegetal (embriones, semillas, inflorescencias, tallos, raíces, meristemos, células individuales, granos de polen, etc.) bajo condiciones asépticas controladas (George y Sherrington, 1984). Las técnicas de CTV han mostrado ser un importante procedimiento en la multiplicación, el mejoramiento y la conservación de las plantas útiles al hombre (Villalobos, 1985). En adición, tales técnicas han sido adaptadas para utilizarse con un amplio rango de 
especies silvestres y han sido aplicadas exitosamente para la germinación en semillas y esporas, rescate de embriones, cultivo de meristemos y de callo (Fay et al. 1999), y han sido empleadas exitosamente en la propagación y conservación de especies en peligro de extinción (Rublúo 1985, Mata et al. 2001 a, b).

El principal uso de la micropropagación ha sido la multiplicación masiva de especies útiles para el hombre (Evans, 1990) y ha demostrado su utilidad práctica en especies de multiplicación deficiente o relativamente lenta como las orquídeas y en plantas que, aunque se pueden reproducir asexualmente mediante esqueje, estolón, bulbo, etc., su número se puede incrementar aún más cuando se propagan in vitro, como es el caso de las plantas de ornato, incluyendo a las orquídeas (Lozoya, 1985). Además de la propagación, con el CTV se pueden realizar estudios básicos de fisiología, genética, bioquímica, bioconversión y producción de compuestos útiles, asimismo se puede incrementar la variabilidad genética, además de que es posible realizar una conservación e intercambio de germoplasma más eficientes (Mroginski y Roca, 1993).

Para poder realizar una efectiva conservación ex situ de las orquídeas y desarrollar programas de uso sustentable adecuados, es factible recurrir a las técnicas del Cultivo de Tejidos Vegetales, que pueden ser utilizadas ampliamente para la propagación y conservación de germoplasma en riesgo o de alto valor ornamental y que han mostrado su efectividad con diversas especies en peligro de extinción (Fay, 1994, Fay et al. 1999, Serna, 1999, Mata et al. 2001b). Así se tiene que muchas orquídeas epífitas y algunas terrestres son cultivadas en ambientes artificiales, y no es inusual que se tengan cientos o miles de individuos creciendo en espacios limitados (Soto 1996). Actualmente hay una cantidad considerable de información acerca del mantenimiento ex situ de orquídeas vía cultivo de tejidos (Soto 1996). A nivel género se tienen reportados para Laelia trabajos sobre micropropagación (Mata y Salazar 2003); en el caso de Epidendrum se han utilizado secciones nodulares (Stewart \& Button 1976), raíces (Churchill et al., 1972), hojas (Churchill et al. 1973), y protoplastos (Yasugi et al. 1986, Oshiro \& Steinhart 1991); para Cattleya la literatura es muy amplia, con reportes sobre el uso de meristemos apicales (Morel, 1964; 1970), brotes laterales (Reinert y Mohr, 1967), secciones de hoja (Champagnat et al., 1970; Arditti, et al., 1971; Fu, 1978; Torres \& Mogollón 2002), protoplastos
(Capesius \& Meyer 1977; Oshiro \& Steinhart 1991) plántulas (Adelberg et al., 1998, Krapiek et al. 2003) y ápices caulinares (Torres \& Mogollón 2000).

Por otra parte, en diversos estudios sobre regeneración in vitro de tejidos de plantas, principalmente leñosas, se ha descrito un evento de desarrollo denominado adquisición de competencia (Ellis \& Bilderback 1989, Lo 1997, Sánchez-Espinosa et al. 2000, Azcón-Bieto \& Talón 2001, Dhaliwal et al. 2003), el cual se define como el potencial endógeno que tiene una célula o tejido para responder a una señal organogénica, la cual activa una ruta particular de diferenciación para desarrollarse de una manera específica a través de un tipo de programación interior o "memoria" (Christianson \& Warnick, citado por Ellis 1989, Hartmann et al. 1990; Lackie 1999, Segura, 2001, Taiz \& Zeiger 2002). Experimentalmente la adquisición de la competencia se puede evaluar exponiendo, a diferentes tiempos (horas a días), los explantes a un medio de cultivo adicionado con reguladores del crecimiento y subcultivandolo a medio libre de reguladores del crecimiento.

Este trabajo describe los protocolos de propagación para las especies estudiadas determinando los tiempos de mayor adquisición de competencia para la mayor formación de brotes y/o PLBs a partir del cultivo in vitro de protocormos de Stanhopea tigrina, Laelia anceps, Epidendrum veroscriptum y Cattleya x Esbetts, orquídeas que están bajo alguna categoría de protección o que poseen un alto valor ornamental; hasta donde sabemos no se han realizado ensayos sobre la adquisición de competencia en la familia Orchidaceae; por lo cual este primer esfuerzo puede ser encaminado a la producción de un gran número de individuos en un menor tiempo y con menos insumos, que sean la base para cubrir la demanda comercial de que son objeto y contribuir de esta manera a disminuir el saqueo y comercio ilegal de individuos silvestres.

\section{Materiales y métodos}

Material BiolóGico empleado. Se utilizaron protocormos de tres especies de orquídeas (Stanhopea tigrina, Laelia anceps, Epidendrum veroscriptum) y un híbrido (Cattleya x Esbetts) provenientes de semillas previamente germinadas en medio basal Murashige y Skoog (MS) (Murashige \& Skoog1962). Las cápsulas fueron colectadas a partir de adultos 
sanos pertenecientes a la colección del Jardín Botánico Clavijero del Instituto de Ecología, A.C. Se emplearon protocormos de $4 \mathrm{~mm}$ de longitud en promedio y que presentaban un estadio de germinación caracterizado por una coloración verde, así como la presencia del primer primordio de hoja y rizoides.

FASE DE INDUCCIÓN. Los protocormos fueron sembrados bajo condiciones asépticas en medio de cultivo MS enriquecido con $100 \mathrm{mg} \mathrm{l}^{-1}$ de myo-inositol, 2 $\mathrm{mg} \mathrm{l}^{-1}$ de glicina y $30 \mathrm{~g} \mathrm{l}^{-1}$ de sacarosa y adicionado con diferentes concentraciones de $\mathrm{N}^{6}$-benciladenina (BA) $(0,1,3$, y 5 mg/l) en combinación de ácido 2,4diclorofenoxiacético (2,4-D) (0 y $0.5 \mathrm{mg} / \mathrm{l})$. El medio fue ajustado a un $\mathrm{pH}$ de $5 \pm 0.1$ con hidróxido de sodio $(\mathrm{NaOH}) 1 \mathrm{~N}$ y/o ácido clorhídrico $(\mathrm{HCl}) 1 \mathrm{~N}$, previo a la adición de $8 \mathrm{~g} / \mathrm{l}$ de agar. El medio de cultivo fue vertido en frascos de vidrio de $120 \mathrm{ml}$ de capacidad y conteniendo $25 \mathrm{ml}$ de medio. Posteriormente se esterilizaron en autoclave durante 15 minutos a una presión de $15 \mathrm{lbs} / \mathrm{psi}$ y una temperatura de $120^{\circ} \mathrm{C}$.

Se sembraron 20 protocormos por tratamiento colocando 10 explantes por frasco. Para determinar con exactitud el periodo de mayor competencia de los explantes con respecto a los diferentes tratamientos de inducción, se llevó a cabo la siembra y subcultivo en 7 tiempos diferentes: 4, 8, 12, 16, 20, 24 y 28 días, con un total de 1,120 explantes utilizados por especie.

Los cultivos fueron incubados para su desarrollo en un cuarto de crecimiento a una temperatura de $25 \pm 2^{\circ} \mathrm{C}$, con fotoperiodo de $16 \mathrm{~h}$ luz y una densidad de flujo fotónico de $50 \mu \mathrm{Mol} \mathrm{m}^{-2} \mathrm{~s}^{-1}$.

FASE DE EXPRESIÓN Y DESARROLlo. Después del periodo de inducción, los protocormos fueron subcultivados a medio MS sin reguladores del crecimiento (Medio basal) para evaluar las respuestas morfogenéticas, posteriormente se realizó un nuevo subcultivo después de mes y medio, al mismo medio basal.

Quincenalmente se registraron por explante la talla de cada individuo, el tipo de respuesta morfogenética que presentaron: número de brotes por explante y/o número de cuerpos semejantes a protocormos (PLBs por sus siglas en inglés).

Los brotes obtenidos a partir de los protocormos de las 4 especies, Stanhopea tigrina, Laelia anceps, Epidendrum veroscriptum y Cattleya $\mathrm{x}$ esbetts se individualizaron después de cuatro meses de iniciado el experimento. Los PLBs obtenidos se contabilizaron.
ANÁlISIS ESTADíSTICO. Los datos obtenidos: número de brotes y PLBs por explante obtenidos a partir de los protocormos cultivados en medio de inducción por diferentes períodos fueron analizados con la ayuda del programa "statistica ver. 2000 ", mediante un análisis de la varianza de una vía (ANOVA) y los tratamientos fueron discriminados mediante la prueba de rango múltiple de Tukey a $\mathrm{p} \leq 0.05$.

\section{Resultados}

FORMACIÓN DE PLBS A PARTIR DE PROTOCORMOS DE $S$. TIGRINA. La formación de PLBs fue bastante heterogénea; sólo en algunos explantes fue posible observar PLBs a los 15 días de haber transferido los explantes a medio basal. La base de los protocormos se hinchó adquiriendo una apariencia rugosa debido a la presencia de varias estructuras nodulares, las cuales fueron hinchándose e incrementando en tamaño hasta formar estructuras esféricas de unos $4 \mathrm{~mm}$ de diámetro en promedio, con un color verde claro, posteriormente cada PLB comenzó a desarrollar primordios foliares y pelos radiculares en su base, este desarrollo se llevó a cabo a lo largo de 4 meses de iniciado el cultivo. Cada PLB se consolidó en una unidad que se desprendía fácilmente de la masa de PLBs y continuaba con su desarrollo, es decir, crecía y formaba una plántula de alrededor de 0.5-1 cm de talla con una o dos hojas.

No se pudo establecer diferencia significativa entre los tratamientos para la formación de PLBs por explante en S. tigrina; sin embargo el tratamiento que indujo la mayor formación de PLBs por explante fue el medio adicionado con 1 y $5 \mathrm{mg} / \mathrm{l}$ de BA y con un período de inducción de 24 días, formando en promedio 8 y 7.8 PLBs por explante en cada caso (Fig. 1); por otro lado, hubo varios tratamientos donde la formación de respuestas morfogenéticas fue nula o muy baja (Tabla 1).

FORMACIÓN DE BROTES A PARTIR DE PROTOCORMOS DE S. TIGRINA. La consolidación y desarrollo de los brotes producidos a partir de protocormos cultivados en medio de inducción durante distintos períodos, se logró después de transferir los explantes a medio basal, y al ser subcultivados nuevamente a los 45 días al mismo medio, donde el número de brotes se incrementó ligeramente.

$\mathrm{Al}$ analizar el conjunto de los tratamientos (concentración de los reguladores del crecimiento y tiempos de inducción) después de 4 meses de cultivo, se pudo establecer diferencia significativa entre los diferentes trata- 


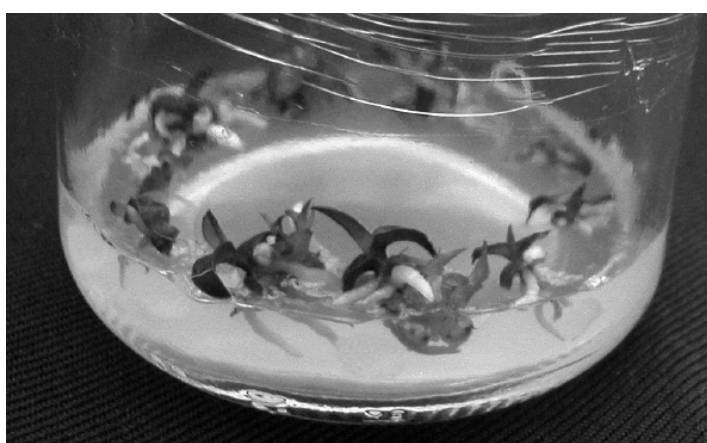

FigurA 1. Formación de PLBs en protocormos de Stanhopea tigrina cultivados con $1 \mathrm{mg} / \mathrm{l}$ de BA y con un período de inducción de 24 días.

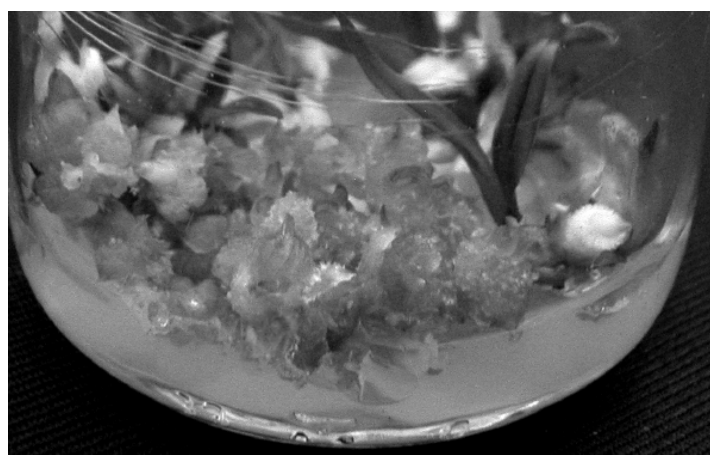

FiguRa 3. Formación de múltiples PLBs a partir de cultivo de protocormos de Laelia anceps en medio MS adicionado con diferentes concentraciones de BA y 2,4-D con un tiempo de inducción de 20 días.

mientos ensayados $(p \leq 0.05)$. Los tratamientos en los que se logró inducir la mayor formación de brotes por explante a partir del cultivo de protocormos de $S$. tigri$n a$, fueron tres: 1) medio adicionado con $5 \mathrm{mg} / \mathrm{l}$ de BA y un tiempo de inducción de 24 días, en el cual se formaron 6.7 brotes por explante (Fig. 2), 2) medio adicionado con $5 \mathrm{mg} / \mathrm{l}$ de BA en combinación de $0.5 \mathrm{mg} / \mathrm{l} \mathrm{de}$ 2,4-D y un tiempo de inducción de 8 días, donde se obtuvo un promedio de 6.4 PLBs; y 3 ) medio adicionado con $5 \mathrm{mg} / 1$ de BA y $0.5 \mathrm{mg} / 1$ de 2,4-D, en un período de inducción de 24 días, donde se obtuvo la mayor formación de brotes por explante (8.7) (tabla 2).

FoRMACIÓN DE PLBS A PARTIR DE PROTOCORMOS DE LAELIA ANCEPS . La formación de PLBs por explante fue muy heterogénea, sin embargo, los resultados en la tabla 3 muestran que la mayor formación de PLBs se dio de manera general en los explantes cultivados en medio de inducción por 20 días para la mayoría de las concentraciones de reguladores empleadas.

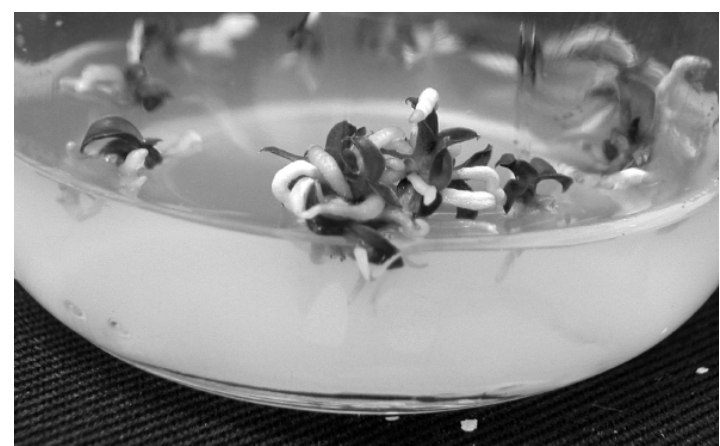

Figura 2. Brotación múltiple en protocormos de Stanhopea tigrina cultivados en medio adicionado con $5 \mathrm{mg} / \mathrm{l}$ de BA y un tiempo de inducción de 24 días.

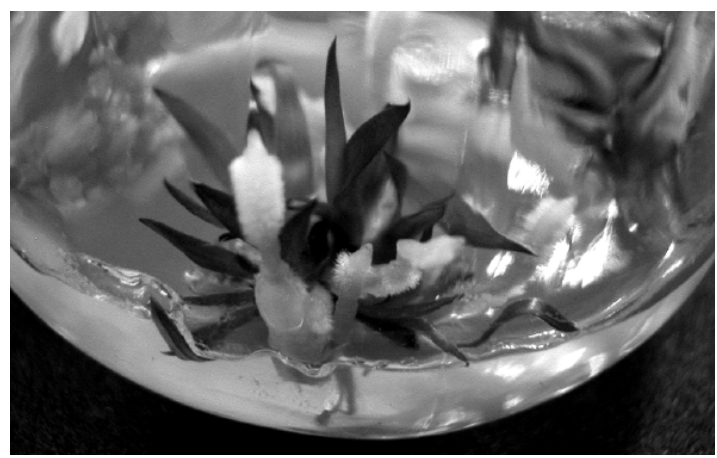

FiguRA 4. Brotación múltiple a partir de cultivo de protocormos de Laelia anceps en medio MS adicionado con $1 \mathrm{mg} / 1$ de BA y $0.5 \mathrm{mg} / 1$ de 2,4-D con 4 días de inducción.

Cuando los explantes se subcultivaron a medio basal, los PLBs incrementaron ligeramente su tamaño, en algunos los PLBs sufrieron hiperhidratación. Cuando los PLBs alcanzaron $4 \mathrm{~mm}$ de diámetro, algunos comenzaron a formar primordios foliares y pelos radiculares, pero después de 4 meses de cultivo muy pocos llegaron a consolidarse como plántulas (Fig. 3).

Al realizar el análisis estadístico para determinar la influencia de los períodos de inducción y las diferentes concentraciones de reguladores empleadas sobre los explantes para la formación de PLBs se pudo establecer una diferencia significativa $(\mathrm{p}=0.000000)$. La adquisición de competencia para la mayor formación de PLBs por explante se obtuvo a los 20 días de inducción en dos tratamientos: 1) medio adicionado con $3 \mathrm{mg} / \mathrm{l}$ de BA, formando 50.6 PLBs por explante; 2) medio adicionado con $5 \mathrm{mg} / \mathrm{l}$ de BA, en el cual se formaron 56.3 PLBs (Tabla 3). 

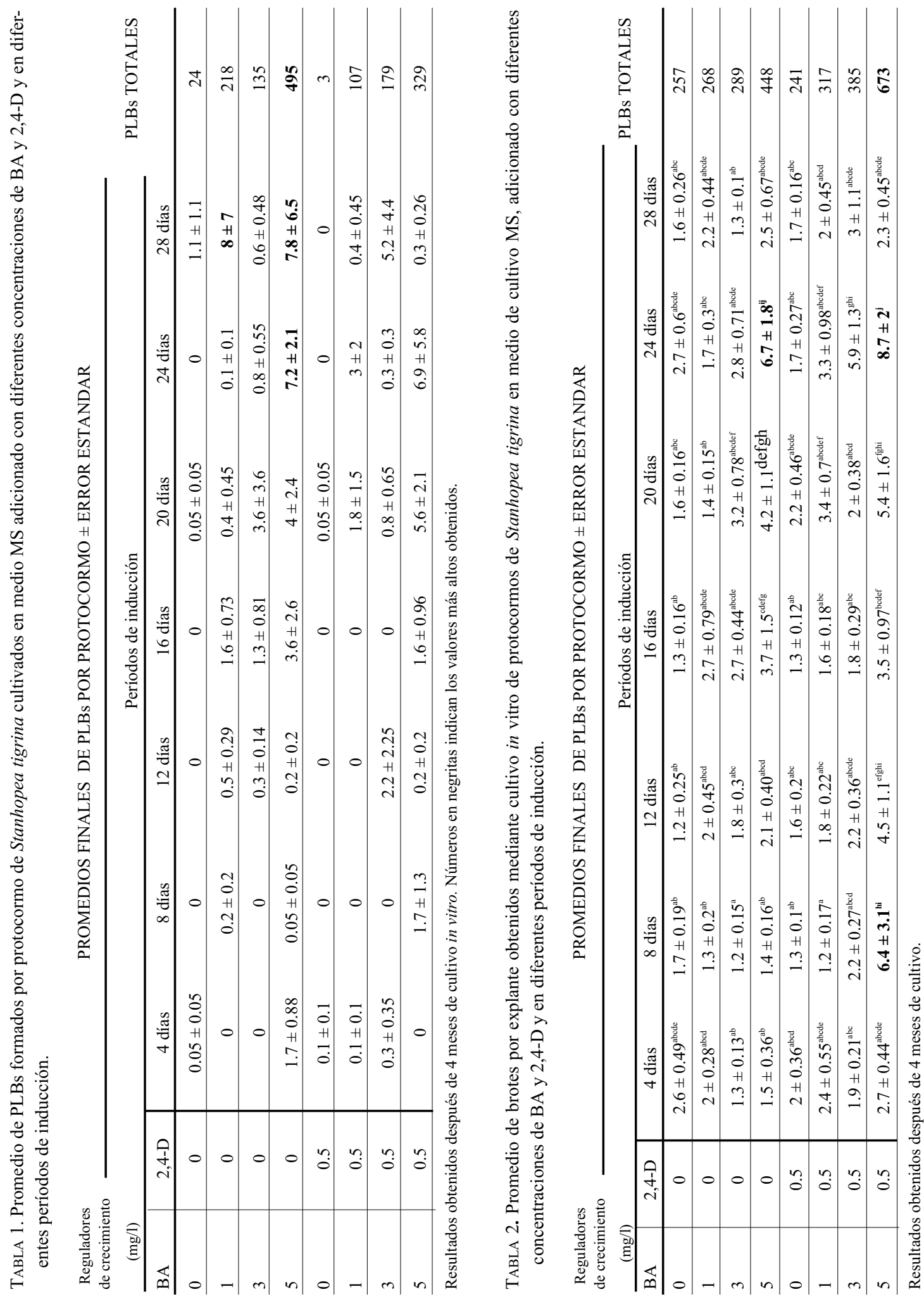


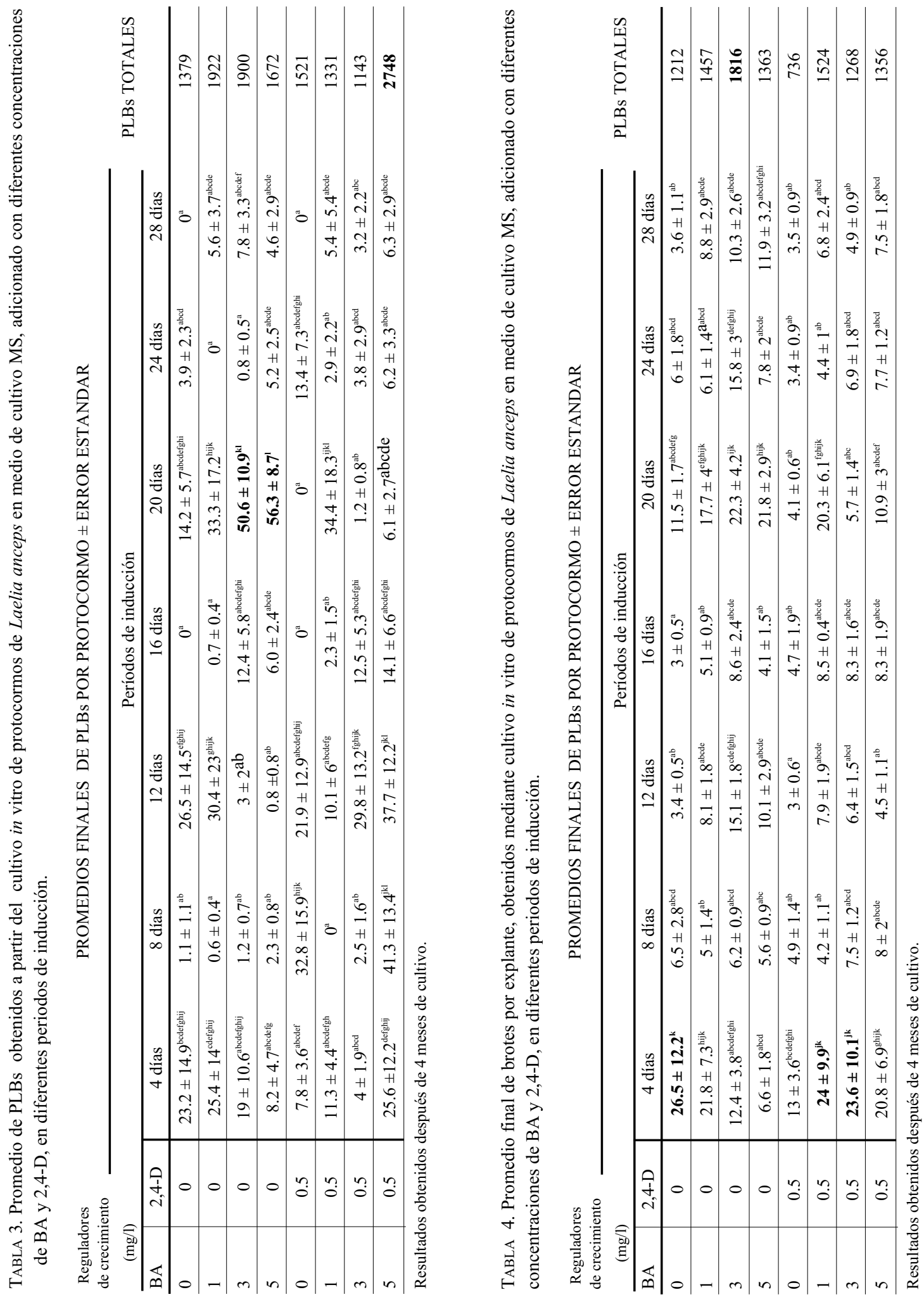




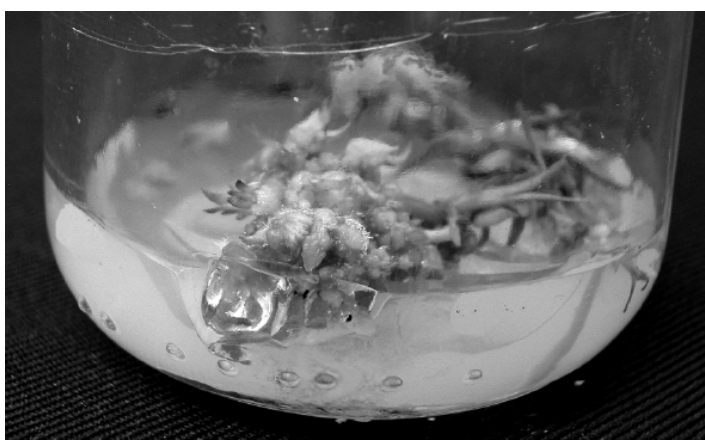

FIGURA 5. Formación de múltiples PLBs en protocormos de Epidendrum veroscriptum cultivados en medio MS con $1 \mathrm{mg} / 1$ de BA en y $0.5 \mathrm{mg} / 1$ de 2,4-D con un tiempo de inducción de 12 días.

FORMACIÓN DE BROTES A PARTIR DE PROTOCORMOS DE $L$. ANCEPS. Para los explantes de $L$. anceps la formación de brotes fue heterogénea. La consolidación y desarrollo de los brotes producidos fue manifestándose después de transferirlos a medio basal, los brotes fueron desarrollando primordios foliares y raíz hasta convertirse en plántulas completas. Cuando fueron subcultivados después de 45 días a medio basal, el número de brotes se incrementó considerablemente, llegando en algunos casos a duplicar o incluso a triplicar la cantidad de brotes producidos por explante.

$\mathrm{Al}$ analizar el efecto del tiempo de inducción para la formación de brotes en el conjunto de los tratamientos después de 4 meses de cultivo, se logró establecer diferencia significativa $(p=0.000000)$ entre las concentraciones y tiempos de inducción utilizadas. De acuerdo con la tabla 4 se observa que el mayor período de inducción se obtuvo en: 1) medio sin reguladores del crecimiento, formando un promedio de 26.5 brotes por explante en un tiempo de 4 días de inducción; 2) medio adicionado con $1 \mathrm{mg} / 1$ de BA en combinación con 0.5 $\mathrm{mg} / \mathrm{l}$ de 2,4-D, que formó 24.9 brotes por explante a los 4 días de inducción (Fig. 4), y 3 ) medio adicionado con $3 \mathrm{mg} / 1$ de BA en combinación con $0.5 \mathrm{mg} / 1$ de 2,4-D, con un promedio de 23.6 brotes. El promedio más bajo para la formación de brotes por explante fue de 3 en dos períodos de inducción: 1) medio sin reguladores del crecimiento, con un tiempo de inducción de 16 días, y 2) el medio adicionado con $1 \mathrm{mg} / \mathrm{l}$ de BA en combinación con $0.5 \mathrm{mg} / 1$ de 2,4-D (tabla 4).

Después de 4 meses de cultivo, $19.19 \%$ del total de los protocormos de $L$. anceps (1120) germinaron y formaron una plántula, con hojas y raíz, solamente en algunos casos

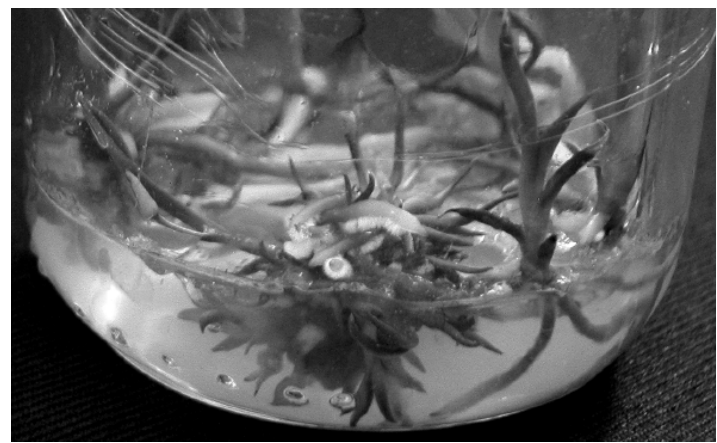

FIGURA 6. Brotación múltiple a partir de cultivo de protocormos de Epidendrum veroscriptum cultivados en medio MS adicionado con $3 \mathrm{mg} / 1$ de BA y $0.5 \mathrm{mg} / 1 \mathrm{de}$ 2,4-D con un tiempo de inducción de 20 días.

formaron pseudobulbos, con una apariencia vigorosa y una coloración verde oscura en las hojas, el $72.41 \%$ presentó respuestas morfogenéticas, como brotes y PLBs. y el $8.39 \%$ del material biológico se perdió debido a necrosis de los protocormos o por contaminación.

FormaCiÓN DE PLBs A PARTIR DE PROTOCORMOS DE E. VEROSCRIPTUM. La formación de PLBs a partir de los protocormos de E. veroscriptum cultivados en diferentes concentraciones de reguladores del crecimiento y en diferentes tiempos de inducción, fue de manera general baja. La mayor formación de PLBs por explante se obtuvo con un tiempo de inducción de 12 días y a partir del control y del tratamiento adicionados con $1 \mathrm{mg} / \mathrm{l}$ de BA en combinación con $0.5 \mathrm{mg} / \mathrm{l}$ de 2,4-D se logró formar 15.3 y 7.2 PLBs por explante en promedio respectivamente (Tabla 5).

Cuando los explantes fueron subcultivados a medio libre de reguladores del crecimiento (MB), la formación y desarrollo de PLBs por explante fue gradual, es decir, los PLBs comenzaron a aparecer como pequeños nódulos, los cuales fueron hinchándose hasta tener una estructura semiesférica, con apariencia rugosa, en todos los casos los PLBs siempre se formaron como estructuras independientes que se desprendían fácilmente del explante original. Cuando los PLBs alcanzaron una talla de $5 \mathrm{~mm}$ en promedio, comenzaron a desarrollar primordio foliar y rizoides (Fig. 5).

ForMACIÓN DE BROTES A PARTIR DE PROTOCORMOS DE $E$. VEROSCRIPTUM. La formación de brotes a partir de los protocormos no fue evidente sino hasta los protocormos fueron subcultivados a medio basal, quince días después era perceptible la formación de primordios de brote. 


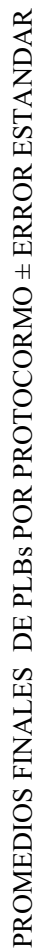

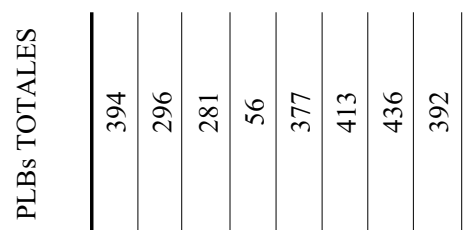

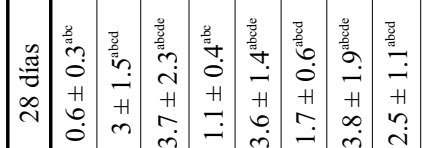

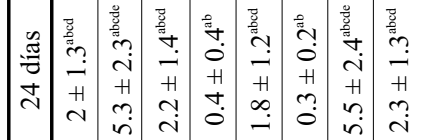

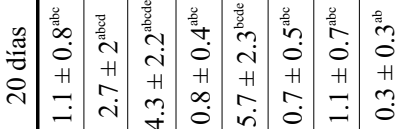

휴

(⿻)

\%

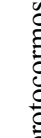

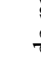

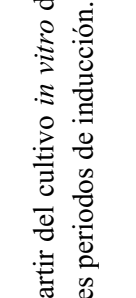

के

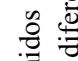

青

ฮั

章

要要

웡

范

的离

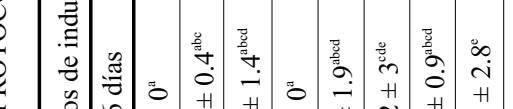

$\stackrel{0}{2}$

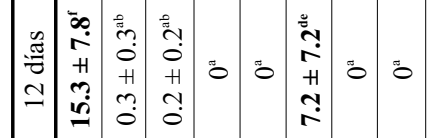

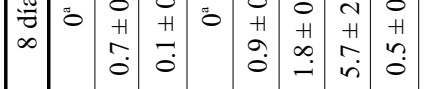

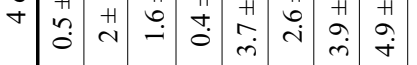

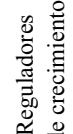

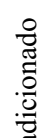

$\sum$

学

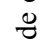

:

ฮี

క.

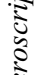

胥

赵

$\approx$

윰

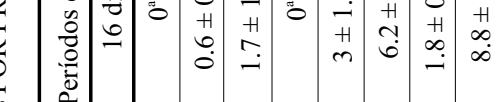

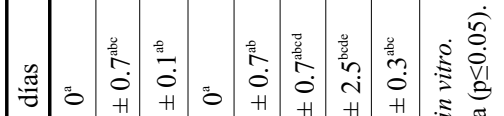

इ

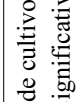

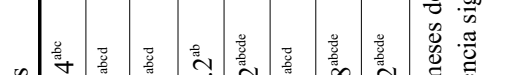

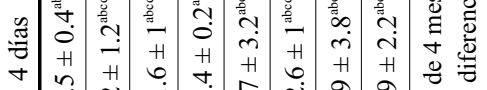
总

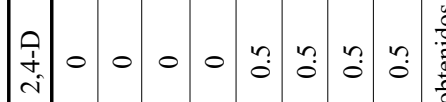

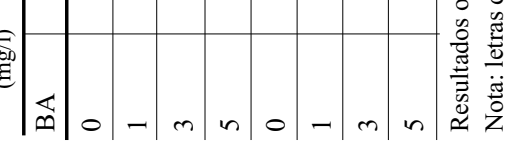
II

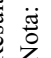

$\frac{0}{2}$

过

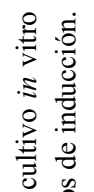

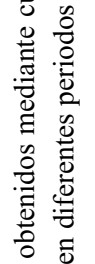

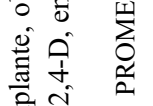<smiles>C#CC#CC</smiles>

告

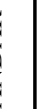

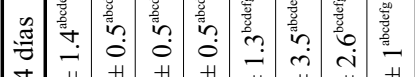

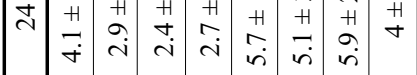

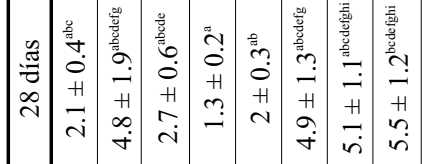

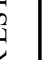

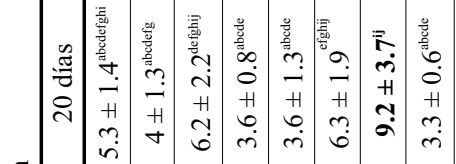

.

然

官

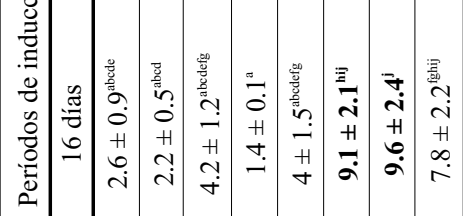

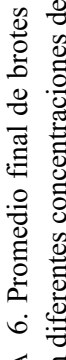

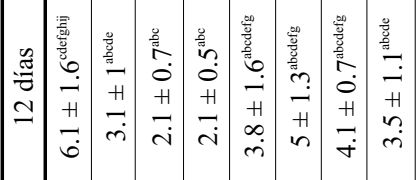

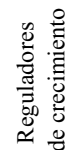

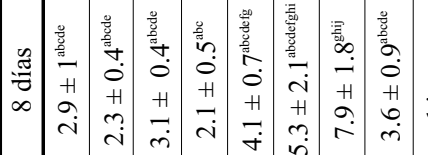

疍

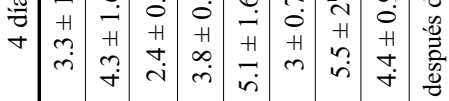

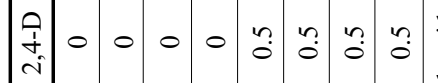

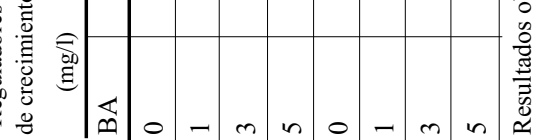




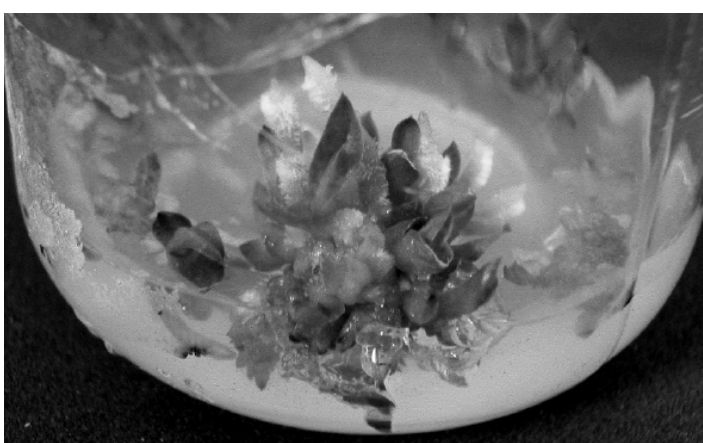

FiguRA 7. Formación de múltiples PLBs a partir de cultivo de protocormos de Cattleya x esbetts cultivados en medio MS adicionado con $3 \mathrm{mg} / 1$ de BA y $0.5 \mathrm{mg} / \mathrm{l} \mathrm{de}$ 2,4-D por 4 días

Al analizar los datos registrados para la formación de brotes por explante fue posible establecer diferencia significativa entre los diferentes tiempos de inducción y concentraciones de reguladores empleadas $(\mathrm{p}=0.001387)$. Los datos en la tabla 6 muestran que la adquisición de competencia para la mayor formación de brotes se obtuvo en tres tratamientos: medio adicionado con $3 \mathrm{mg} / 1$ de BA y $0.5 \mathrm{mg} / 1$ de 2,4-D los cuales, con períodos de 16 días y 20 días de inducción, formaron 9.6 y 9.2 brotes por explante respectivamente y medio de cultivo adicionado con $1 \mathrm{mg} / \mathrm{l}$ de BA y $0.5 \mathrm{mg} / \mathrm{l} \mathrm{de}$ 2,4-D, con un período de inducción de 16 días, formaron 9.1 brotes por explante en promedio (Fig. 6).

\section{Cattleya $\mathrm{x}$ Esbetts}

FORMACIÓN DE PLBS A PARTIR DEL CULTIVO IN VITRO DE PROTOCORMOS DE $C$. X ESBETTS. Al analizar el efecto que tuvieron los períodos de inducción en los explantes para la formación de PLBs entre los tratamientos ensayados, fue posible establecer diferencia significativa $(\mathrm{p}$ $=0.000208$ ). En la tabla 7 se puede observar que la formación de PLBs fue en general baja, y solamente en algunos tratamientos se obtuvo una gran cantidad de PLBs por explante. La mayor formación de PLBs se obtuvo a partir de los explantes cultivados en medio de inducción por 4 días en dos tratamientos, el adicionado con $3 \mathrm{mg} / 1$ de BA y $0.5 \mathrm{mg} / 1$ de 2,4-D, los cuales produjeron un promedio de 22.2 PLBs por explante y en el medio adicionado con $1 \mathrm{mg} / \mathrm{l}$ de BA y $0.5 \mathrm{mg} / 1$ de $2,4-$ D, en donde los explantes formaron 20.8 PLBs en promedio (Fig. 7). En algunos tratamientos no se obtuvo la formación de PLBs, principalmente con un tiempo de inducción de 12 días (tabla 7).

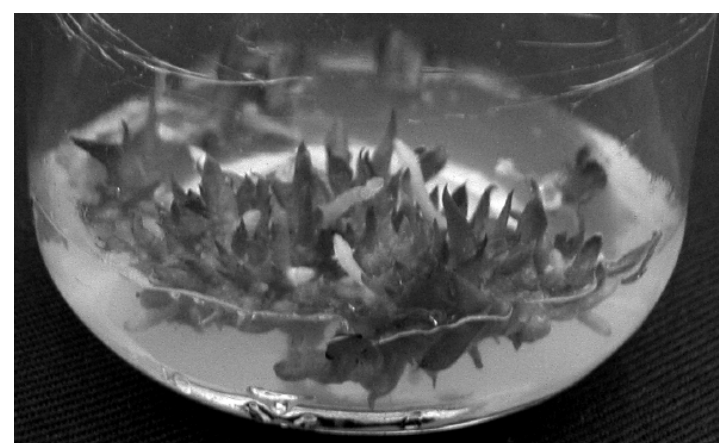

FIGURA 8. Brotación múltiple a partir de cultivo de protocormos de Cattleya x esbetts cultivados en medio MS adicionado con $1 \mathrm{mg} / \mathrm{l}$ de BA con un período de inducción de 20 días.

FORMACION DE BROTES A PARTIR DEL CULTIVO DE PROTOCORMOS DE CATTLEYA X EsBEtTs. Al analizar el efecto de los períodos de inducción para la formación de brotes por explante, fue posible establecer diferencia significativa ( $\mathrm{p} \leq 0.5$ ). Los datos en la tabla 8 muestran que la adquisición de competencia para la mayor formación de brotes por explante se obtuvo en tres tratamientos: 1) en medio MS adicionado con $1 \mathrm{mg} / \mathrm{l}$ de BA en un período de inducción de 20 días, donde se obtuvo una formación promedio de 18.7 brotes por explante; 2) en medio MS adicionado con $3 \mathrm{mg} / \mathrm{l}$ de BA por 16 días, donde se logró una formación de 17.8 brotes por explante en promedio; 3) en el medio adicionado con $3 \mathrm{mg} / \mathrm{l}$ de BA y $0.5 \mathrm{mg} / \mathrm{l}$ de 2,4-D, con un período de inducción de 28 días, obteniendo un promedio de 16.5 brotes por explante (Fig. 8). Por el otro lado, la menor capacidad regenerativa para la formación de brotes se registró en los explantes cultivados en medio de inducción adicionado con $1 \mathrm{mg} / 1$ de BA por 28 días, los cuales formaron alrededor de 0.9 brotes por explante (tabla 8 ).

\section{Discusión}

USO DE PROTOCORMOS EN LA MICROPROPAGACIØÓN.

Los protocormos derivados de semillas de orquídeas fueron una importante fuente de explante para los propósitos de este trabajo, pues se sabe que las semillas son el material de diversidad genética por excelencia que se debe tomar en cuenta cuando se requiere recuperar especies que se encuentren amenazadas, pues garantizan una estabilidad y diversidad genética (Martínez, 1985). Los protocormos pueden ser utilizados lo mismo para incrementar su talla y consolidarlos como plántulas, como es el caso del trabajo de Fonnesbech (1972), 


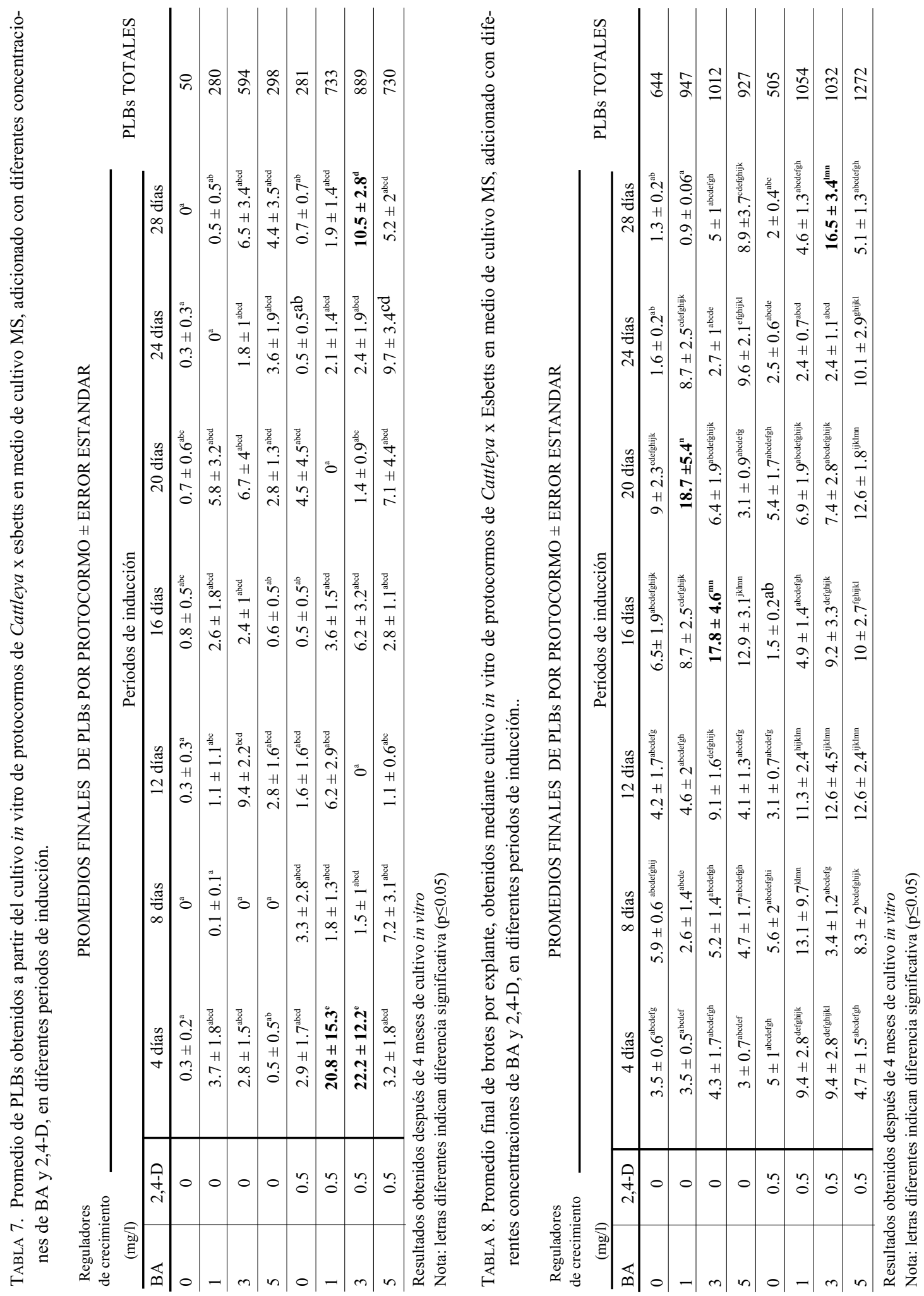


o bien para que sigan una ruta específica de desarrollo (Ramírez, 1990; Park et al., 2002; Faria et al., 2004; Ket et al., 2004 y Malabadi et al., 2005). Aunque se utilizó la misma técnica de cultivo para las cuatro especies estudiadas (cultivo de protocormos en medio de inducción MS y posteriormente medio basal) los resultados fueron diferenciales, ya que las concentraciones de los reguladores de crecimiento y los tiempos de inducción empleados fueron diferentes y se obtuvieron respuestas morfogenéticas distintas.

La principal respuesta a partir del cultivo de protocormos de L. anceps, E. veroscriptum y Cattleya $\mathrm{x}$ esbetts fue la formación de PLBs, mientras que en Stanhopea tigrina fue la formación de brotes. Baltazar (2004) reporta en su trabajo que la principal respuesta al cultivo in vitro de protocormos enteros en medio $\mathrm{KC} \mathrm{y}$ MS con combinaciones factoriales de reguladores del crecimiento fueron brotes adventicios, mientras que a partir de mitades de protocormos la principal respuesta que obtuvo fue la formación de PLBs. Shyamal y Pinaki, (2004) obtuvieron regeneración de brotes a partir del cultivo de semillas de Vanda teres (Roxb.) Lindl. en medio Vacin and Went adicionado con $1.0 \mathrm{mg} / 1$ BAP y $0.5 \mathrm{mg} / 1$ ANA. Por su parte, Lu (2004) consiguió una alta brotación a partir del cultivo de protocormos de Pleione formosana Hayata en medio MS al $50 \%$ adicionado con $5 \mathrm{mg} / \mathrm{l}$ de 2,4-D y $0.5 \mathrm{mg} / 1 \mathrm{de}$ Tidiazurón. Además, Cacalvante et al., (2001) promovieron la expresión de respuestas morfogenéticas vía organogénesis indirecta a partir de protocormos cultivados en medio MS adicionado con 0.5 y $1 \mathrm{mg} / \mathrm{l}$ de BAP en Góngora quinquenervis, Por último, Bhadra y Hossain (2003) también obtuvieron diferentes respuestas morfogenéticas a partir del cultivo de protocormos de Geodorum densiflorum (Lam.) Schltr. en medio MS adicionado con diferentes combinaciones de reguladores del crecimiento.

EFECTO DE LOS TRATAMIENTOS EN LA ADQUISICIÓN DE COMPETENCIA PARA LA FORMACION DE PLBS.

En todas las especies estudiadas los PLBs fueron inducidos directamente a partir de los explantes originales de cada una de las especies y la respuesta a la inducción fue heterogénea. La mayor formación de PLBs se presentó principalmente en $L$. anceps con 20 días de inducción y con altas concentraciones de BA (3 y 5 $\mathrm{mg} / \mathrm{l})$ y en ausencia de 2,4-D, donde se indujo la formación de 50 a 56 PLBs por explante en promedio, en
Cattleya $\mathrm{x}$ esbetts, cuyos explantes cultivados en medio con BA ( 1 y $3 \mathrm{mg} / \mathrm{l}$ ) en presencia de 2,4-D por 4 días, los cuales promovieron la formación de 20 a 22 PLBs por explante al final del experimento. En el caso de $E$. veroscriptum, la capacidad regenerativa más alta para la formación de PLBs se obtuvo con 12 días de inducción, tanto en el medio sin reguladores del crecimiento como el medio con una baja concentración de BA $(1 \mathrm{mg} / \mathrm{l})$ y 2,4-D, mientras que la concentración más alta de BA en ausencia de 2,4-D inhibió la formación de PLBs en los explantes cultivados. Por su parte, los explantes de $S$. tigrina cultivados en medio de inducción por 28 días tuvieron una fuerte influencia de BA en ( 1 y $3 \mathrm{mg} / \mathrm{l}) \sin$ 2,4-D, así como en altas concentraciones de BA en presencia de 2,4-D, las cuales promovieron la mayor formación de PLBs, mientras que bajas concentraciones de BA con 2,4-D inhibieron fuertemente la producción de PLBs, estos resultados contrastan con lo reportado por Mata y Salazar (2003), pues ellos obtuvieron la mayor formación de PLBs en protocormos de Cuitlauzinia pendula que fueron cultivadas en medio MS sin reguladores de crecimiento y en medio adicionado con 0.5 $\mathrm{mg} / \mathrm{l}$ BA por 4 meses. Lo anterior demuestra que los requerimientos para la inducción (micropropagación) de las diferentes especies de orquídeas, es decir, medio de cultivo, concentración de reguladores del crecimiento y tiempo de inducción, deben ser determinadas experimentalmente.

EFECTO DE LOS TRATAMIENTOS EN LA ADQUISICIÓN DE COMPETENCIA PARA LA FORMACION DE BROTES.

Para L. anceps la mayor formación de brotes, 26.5 brotes por explante, se obtuvo con 4 días de inducción en medio MS sin reguladores de crecimiento. Ha sido demostrado que algunas veces, no siempre se requiere de los reguladores del crecimiento para obtener la respuesta morfogenética adecuada, ya que puede lograrse por medio de factores físicos o químicos que afectan la movilización, producción o inhabilitación de los reguladores del crecimiento en el explante; los niveles endógenos de los reguladores son influenciados por la duración, calidad e intensidad de la luz y por factores químicos ambientales, tales como macro y micronutrientes, además, la activación o inactivación de las rutas metabólicas por la biosíntesis de aminoácidos aromáticos y la respiración pueden cambiar los niveles endógenos hormonales en el explante (Bonga y Aderkas, 1992).

En Cattleya x Esbetts la presencia de BA fue deter- 
minante para la mayor inducción de brotes por explante, logrando inducir la formación hasta 18.7 brotes por explante en aquellos explantes cultivados únicamente con $1 \mathrm{mg} / \mathrm{l}$ de BA, este resultado concuerda con lo reportado por Arditti (1992), quien afirma que después de varios estudios realizados en Cattleya, las combinaciones óptimas para la formación de brotes para este género fue $1 \mathrm{mg} / 1$ de BA y $0.5 \mathrm{mg} / 1$ de ANA. Es frecuente encontrar reportes en la propagación in vitro de orquídeas el uso de bajas concentraciones de citocininas con nulas y muy bajas concentraciones de auxinas, Baltazar (2004) reporta que las mejores respuestas morfogenéticas en el cultivo de protocormos enteros de Oncidium tigrinum en medio de cultivo MS con una concentración similar $(0.1 \mathrm{mg} / \mathrm{l}$ de ANA y $1 \mathrm{mg} / \mathrm{l} \mathrm{de}$ BA), mientras que Krapiec et al., (2003) obtuvieron una alta brotación a partir de protocormos cultivados en medio B5 con diferentes combinaciones de BA y AIB. Por su parte, George y Ravishankor (1997) mencionan en su trabajo con Vanilla plannifolia que obtuvieron respuestas morfogenéticas en medio adicionado con 2 $\mathrm{mg} / \mathrm{l}$ de BA y $1 \mathrm{mg} / \mathrm{l}$ de ANA.

En S. tigrina y E. veroscriptum se logró la inducción de brotes entre los 16 y los 24 días con altas concentraciones de BA en presencia de 2,4-D, obteniendo entre 8 y 9 brotes por explante. Además, se ha podido constatar de manera general, que la presencia de 2,4-D en el medio inhibió la multiplicación de brotes, lo cual no afectó su crecimiento, alcanzando en algunos casos las tallas más altas para cada especie, lo cual es similar nuevamente con lo que reporta Arditti (1992), quien determinó que muy bajas concentraciones $(0.1 \mathrm{mg} / \mathrm{l})$ de ANA o 2,4-D promueven el crecimiento de los explantes.

\section{Conclusiones}

Es muy común encontrar en la literatura referente a la propagación de orquídeas y otras especies tiempos de inducción que van de 30 a 60 días y son muy pocos los que mencionan estudios específicos para determinar los tiempos de adquisición de competencia, la gran mayoría de trabajos de este tipo se han realizado con coníferas y no hemos encontrado ninguno con orquídeas, por lo que este trabajo puede considerarse pionero en la investigación acerca de la adquisición de competencia en esta familia. El poder determinar con una mayor precisión el momento en que el explante a cultivar adquiere competencia para la formación de brotes y/o PLBs no sólo se logrará inducir la mayor cantidad de regenerantes por explante, sino que también se podrán reducir los tiempo y costos de producción, teniendo como consecuencia, material suficiente que pueda ser usado ya sea para realizar otro tipo de estudios (anatómico, fisiológico, genético, ecológicos etc.) o plantas de las especie silvestres que puedan ser usadas para satisfacer el comercio legal con lo que se estará contribuyendo a disminuir la presión de colecta, en muchos casos ilegal, de sus poblaciones silvestres, con le que se estará incidiendo directamente con la conservación y uso sustentable de este valioso recurso natural. En caso de los híbridos con alto valor ornamental y de las mismas especies el poder reducir los tiempos y costos de producción y contar con plantas sanas y vigorosas será posible ofrecerlas al consumidor de manera controlada y a precios altamente competitivos y accesibles.

\section{LITERATURA CITADA}

Adelberg, J., R. Pollock, N. Rajapakse \& R. Young. 1998. Micropropagation, decontamination, transcontinental shipping and hydroponic growth of Cattleya while sealed in semipermeable membrane vessels. Scientia Horticulturae 73:23-35.

Arditti, J., E.A. Ball \& M.E. Churchill. 1971. Propagación clonal de orquídeas utilizando ápices de hojas. Orquídea (Mexico) 2: 290-300.

Arditti, J. 1992. Fundamentals of orchid biology. John Wiley and Sons. U. S. A. 691 p.

Ávila, I. \& K. Oyama. 2002. Manejo sustentable de Laelia speciosa (Orchidaceae). Biodiversitas. 7(43):9-12.

Azcón-Bieto, J. \& M.Talón. 2001. Capítulo 18. Fundamentos de fisiología vegetal. $2^{\text {da }}$ reimpresión. Mc Graw-Hill. Interamericana de España. Edicions Universitat de Barcelona. España. 522 p.

Baltazar, R. 2004. Micropropagación de Oncidium tigrinum Llave y Lex. (Orchidaceae) a partir de protocormos. Tesis de licenciatura (Biología). Universidad Veracruzana. Xalapa, Ver. 124 p.

Bechtel, H., P. Cribb \& E. Launert. 1981. The manual of cultivated orchid species. The MIT Press. Cambridge. $443 \mathrm{p}$.

Bhadra, S. \& M. Hossain. 2003. In vitro Germination and Micropropagation of Geodorum densiflorum (Lam.) Schltr., an Endangered Orchid Species. Pl. Tissue Cult. 13(2): 165171.

Bonga, J. \& P. Aderkas. 1992. In vitro culture of trees. Kluwer Academic Publishers. The Netherlands. 209 p.

Capesius I. \& Y. Meyer. 1977. Isolation of nuclei from protoplasts of orchids. Cytobiol. 15: 485-490.

Cavalcante, P., L. Willadino, G. Dias \& V. Tenorio. 2001. Pesq. Agropec. Bras., Brasil. 36(10): 1319-1324. 
Champagnat, M., G.Morel \& B. Mounetou. 1970. La multiplication végétative des Cattleya é partir de jeunes feuilles cultivées in vitro. Ann. Sc. Nat. Bot. Biol. Vég. (Sér. 12) 11: 97-114.

Churchill, M.-E., E.A. Ball \& J. Arditti. 1972. Tissue culture of orchids. II. Methods for root tips. Amer. Orchid Soc. Bull. 41: 726-730.

Churchill, M.-E., E.A. Ball \& J. Arditti. 1973. Tissue culture of orchids. I. Methods for leaf tips. New Phytol. 72:161-166.

Dhaliwal, H., N. Remesar-Forther, E. Yeung \& T. Thorpe. 2003. Competence, determination, and meristemoid plasticity in tobacco organogenesis in vitro. Canadian Journal of Botany. Ottawa. Vol. 81, 1ss. 6; p. 611.

Dixon, K.W., S.P.Kell \& P.J. Cribb (eds.). 2003. Orchid Conservation. Natural History Publications (Borneo), Kota Kinabalu, Sabah. Pp. 259-288.

Dressler, R. L. 1993. Phylogeny and classification of the orchid Family. Dioscorides Press. Portland, Oregon. 313 p.

Ellis, D. \& D.Bildebarck. 1989. Temporal competence of embryonic Pinus ponderosa cotyledons to form multiple buds in vitro. Amer. J. Bot. 76(3): 348-355.

Espejo, A., J. García, A. López, R. Jiménez \& L. Sánchez. 2002. Orquídeas del estado de Morelos. Orquídea (Méx.) Volumen 16. México, D. F. 332 p.

Evans, M. 1990. Micropropagation: Axillary bud multiplication. Pp. 93-103 in: J.Y. Pollard \& J. Walker (eds.). Methods in molecular biology. Vol. 6. Plant cell and tissue culture. Human Press. Clifton, New Jersey.

Faria, R., F. Rodríques, L. Oliveira \& C. Müller. 2004. In vitro Dendrobium nobile plant growth and rooting in different sucrose concentrations. Horticult. Brasil., Brasilia. 22(4):780-783.

Fay, M. F. 1994. In what situations is in vitro culture appropriated to plant conservation? Biodivers. Conserv. 3: 176-183.

Fay, M., E. Bunn \& M. Ramsay. 1999. In vitro propagation. A color Atlas of Plant Propagation and Conservation. Bowes, B. (ed.). The New York Botanical Garden Press. Bronx, New York. 224 p.

Fonnesbech, M. 1972. Organic Nutrients in the Media for Propagation of Cymbidium in vitro. Physiol. Plant. 27(3), 360-364.

Fu, F.M.L. 1978. Clonal propagation of Aranda, Ascocenda, and Cattleya by leaf tissue culture. Gardens Bull. (Singapore) 31: 132-138.

García-Cruz, J. \& L. Sánchez. 1999. Orchidaceae II. Epidendrum. Flora de Veracruz. Fascículo 112. Instituto de Ecología, A. C. Xalapa, Ver. México

George, E. \& Sherrington. 1984. Plant propagation by tissue culture. Handbook and directory of commercial laboratories. Exagetic Limited, England. 709 p.

George, P. \& G. Ravishankor. 1997. In vitro multiplication of Vanilla planifolia using axillary bud explants. Pl. Cell
Reports. 16(7):490-494.

Hágsater, E. 1971. Las Cattleyas. Orquídea (Méx.). 1(2): 3-8.

Hágsater, E. \& A.M.A. Soto. 2001. Orchid conservation in México. Pp. 18-22 in: W.E. Higgins \& B.W. Walsh (eds.) Orchid conservation proceedings. Selby Botanical Gardens Press, Sarasota.

Halbinger, F. \& M. Soto. 1997. Laelias of Mexico. Orquídea (Méx.). 15(1): 37, 38, 40, 41, 50 y 61.

Hartmann, H., D. Kester \& F. Davies Jr. 1990. Plant propagation. Fifth edition. Prentice Hall. New Jersey. 647 p.

IUCN/SSC Orchid Specialist Group. 1996. Orchids - Status Survey and Conservation Action Plan. IUCN, Gland Switzerland and Cambridge, UK.

Jiménez, M. R., S.L. Sánchez \& J. García-Cruz. 1998. Familia Orchidaceae. Tribu Maxillarieae. Flora del Bajío y de regiones adyacentes. Fascículo 67. 83 p.

Ket, N., E. Hahn, S. Park, D. Chakrabarty \& K. Paek. 2004. Micropropagation of an Endangered Orchid Anoectochilus formosanus. Biol. Plant. 48(3):339-344.

Krapiek, P., M. Milaneze \& M. da Silva. 2003. Effects of different combinations of growth regulators for bud induction from seedlings of Cattleya walkeriana Gardner (Orchidaceae). Acta Scientiarum: Biological Sciences. Maringá, 25 (1):179-182.

Lackie, J. \& J. Dow. 1999. The dictionary of cell and molecular biology. Third edition. Academic Press. P. 110.

Lo, K., K. Giles \& V. Swhney. 1997. Acquisition of competence for shoot regeneration in leaf discs of Saintpaulia ionantha $x$ confusa hybrids (African violet) cultured in vitro. Pl. Cell Rep. 15:416-420

Lozoya, S. H. 1985. Micropropagación de especies herbáceas. Pp. 65-79 in: M.L. Robe \& V.M. Loyola (eds.). El cultivo de tejidos vegetales en México. CICY. México.

Lu, M. 2004. High Frequency Plant Regeneration from Callus Culture of Pleione formosana Hayata. Pl. Cell Tiss. Organ Cult. 78 (1):93-96.

Malabadi, R., G. Mulgund \& N. Kallappa. 2005. Micropropagation of Dendrobium nobile from shoot tip sections. J. Pl. Physiol. 162(4): 473-478.

Martínez, A. 1985. Inducción in vitro de brotación múltiple en Bletia urbana Dressler (Orchidaceae) a partir de protocormos seccionados. Tesis profesional. Facultad de Ciencias. UNAM. México, D. F. 66 p.

Mata, R.M., A.V.M. Chávez, \& B.R. Bye. 2001a. In vitro regeneration of plantlets from immature zygotic embryos of Picea chihuahuana Martínez, an endemic Mexican endangered species. In Vitro Cell Development Biology-Plant 37:73-78.

Mata, R. M., M.A. Monroy de la Rosa, G.K. Moebius \& A.V. M. Chávez. 2001b. Micropropagation or Turbinicarpus laui Glass et foster, an endemic and endangered species. In Vitro Cell Developmental Biology - Plant 37:400-404.

Mata, M. \& V. Salazar. 2003. Micropropagación y conserva- 
ción de orquídeas mexicanas en el Jardín Botánico Clavijero. Lankesteriana 7:151-153.

Morel G. 1964. Régénération des Variétiés virosées par la culture des méristémes apicaux. Rev. Hortic. 136: 733-740.

Morel G. 1970. Neues auf den Gebiet der MeristemForschung. Die Orchidee 20: 433-443.

Mroginski, L. \&W. Roca. 1993. Capítulo 2. Establecimiento de cultivo de Tejidos Vegetales in vitro. Cultivo de tejidos en la agricultura. Primera reimpresión. Centro Internacional de Agricultura Tropical (CIAT). Cali, Colombia. 969 p.

Murashige, T. \& F. Skoog. 1962. A revised medium for rapid growth and bioassays with tobacco tissue culture. Physiologia Plantarum 15:473-494.

SEMARNAT. 2002. Norma Oficial Mexicana NOM-059ECOL-2001. Protección ambiental-Especies nativas de México de flora y fauna silvestres-Categorías de riesgo y especificaciones para su inclusión, exclusión o cambio-Lista de especies en riesgo. Diario Oficial (6 de marzo 2002). México, D.F.

Oshiro M.A. \& W.L. Steinhart. 1991. Preparation of protoplasts from cells of orchids representing various genera. Lindleyana 6: 36-41.

Park, S., E. Yeung, D. Chakrabarty \& K. Paek. 2002. An efficient direct induction of protocorm-like bodies from leaf subepidermal cells of Doritaenopsis hybrid using thin-section culture. Plant Cell Reports. 21(1):46-51

Ospina, H. M. 1996. Orchidology and biotechnology. Orchids. October. 1072-1074.

Quintanar, A. 1961. Las plantas ornamentales, SAG. pp. 113117.

Ramírez, C. 1990. Establecimiento del cultivo in vitro de orquídeas mexicanas en peligro de extinción. Tesis de Licenciatura (Biólogo). Facultad de ciencias. UNAM. México, D. F. 64 Págs.

Reinert, R.A \& Mohr H.C. 1967. Propagation of Cattleya by tissue culture of lateral bud meristems. Proc. Amer. Soc. Horticult. Sc. 91: 664-671.

Rublúo, A. 1985. Estrategias para la preservación del germo- plasma vegetal in vitro. In: M. Robert \& Loyola (eds.). El cultivo de tejidos vegetales en México. Primera edición. CICY, CONACYT. 161 p.

Salazar R.V.M. 2003. Micropropagación de Mormodes tuxtlensis Salazar, Cuitlauzina pendula La Llave \& Lex. y Lycaste skinneri (Batem. Ex. Lind.) lind. (Orchidaceae) a partir de protocormos. Tesis de licenciatura. Escuela de Biología. Benemérita Universidad Autónoma de Puebla. México. 106 p.

Sánchez-Espinoza, C., A. Jiménez, K. Moebius, A. Alvarez, V. Cervantes, I. Vargas, S. Luna, P. Ortega, A. Martínez, A. López, P. Olguín, M. Mata, M. Monroy, V. Chávez \& R. Bye. 2000. Regeneración in vitro de especies mexicanas en peligro de extinción. Amaranto. 13(1): 12-19.

Segura, J. 2001. Fundamentos de fisiología vegetal. Capítulo 18. Introducción al desarrollo. Concepto de hormona vegetal. Azcon-Bieto, J y Talón, M. (Eds). 2da reimpresión. Mc Graw-Hill. Interamericana de España. Edicions Universitat de Barcelona. España. 522 p.

Serna, G.M.D. 1999. Biotecnología vegetal y conservación. Cuad. Biodivers. 2(1): 9-11.

Shyamal, K. \& S. Pinaki. 2004. Regeneration of an Indigenous Orchid, Vanda teres (Roxb.) Lindl. Through In vitro Culture. Plant Tissue Culture. 14 (1): 55-62 (2004).

Sosa V. \& T. Platas. 1998. Extinction and persistence of rare orchids in Veracruz, México. Conservation Biology. 12(2): 451-455.

Soto, M. 1996. Orchids. In: A.M. Pridgeon (ed.). Unión Internacional para la Conservación de la Naturaleza y sus Recursos. Gland Switzerland. 153 p.

Soto, M. 2002. Plate 678 in: E. Hágsater \& M.A. Soto (eds.). Icones Orchidacearum 5-6. Herbario AMO, México, D. F.

Stewart J. \& J. Button. 1976. Rapid vegetative multiplication of Epidendrum O'brienianum in vitro and in the greenhouse. Amer. Orchid Soc. Bull. 45: 922-930.

Taiz, L. \& E. Zeiger. 2002. Plant physiology. Third edition. Sinauer Associates, Inc. Publishers. Sunderland, Massachusetts. 690 p.

Mario S. Tinoco Juárez es biólogo egresado de la Universidad Nacional Autónoma de México. Realizó su tesis en el Instituto de Ecología A. C. El presente trabajo es resultado de su trabajo de tesis. Está interesado en profundizar sus conocimientos en el área de la biotecnología vegetal, así como ayudar en la conservación y manejo sustentable de orquídeas mexicanas.

Martín Mata Rosas es Investigador asociado C adscrito a la Unidad de Recursos Forestales del Instituto de Ecología, en los últimos años ha dedicado, mediante las técnicas de cultivo de tejidos, al estudio, propagación y conservación de la flora del bosque mesófilo de montaña con énfasis en las especies en peligro de extinción. 